\title{
Occupational infection to Brucella abortus B19 vaccine despite antimicrobial prophylaxis
}

\author{
Infecção ocupacional pela cepa vacinal de Brucella abortus B19 apesar de \\ profilaxia antimicrobiana
}

Alexandre Sampaio Moura ${ }^{1}$ (D), Letícia Mattos Menezes² (D), Marcelle Amaral de Matos ${ }^{3}$ (D), Cynthya Magalhães Costa 3 (D), Bruna Arantes Borges ${ }^{3}$ (D)

\begin{abstract}
The authors report the case of a veterinarian who acquired brucellosis infection by accidental exposure to Brucella abortus vaccine (BRUCEL-VET B19) while performing animal vaccination. Antibiotic prophylaxis with doxycycline and rifampin for six weeks was indicated, but rifampin was discontinued after 10 days due to gastrointestinal intolerance. Despite prophylaxis, the patient seroconverted after 30 days, but was asymptomatic and did not require additional antibiotic therapy. Post-exposure prophylaxis of Brucella is not free from side effects and asymptomatic seroconversion can occur despite prophylaxis.
\end{abstract}

Keywords: Brucellosis; Occupational Exposure; Post-Exposure Prophylaxis.

\section{RESUMO}

Os autores relatam o caso de um veterinário que adquiriu infecção por brucelose por exposição acidental à vacina Brucellaabortus (BRUCEL-VET B19) durante a vacinação animal. A profilaxia antibiótica com doxiciclina e rifampicina por seis semanas foi indicada, mas a rifampicina foi descontinuada após 10 dias devido à intolerância gastrointestinal. A profilaxia pós-exposição de Brucella não está isenta de efeitos colaterais e a soroconversãoassintomática pode ocorrer apesar da profilaxia.

Palavras-chave: Brucelose; Exposição Ocupacional; Profilaxia Pós-Exposição.

\section{INTRODUCTION}

Brucellosis is a bacterial zoonosis responsible for more than half a million new human cases annually, mainly in developing countries ${ }^{1}$. Ingestion of contaminated food and occupational contact remain the major sources of infection, and accidental exposure rarely results in human brucellosis ${ }^{2}$.

Fever, sweating, arthralgia and myalgia are common clinical manifestations in brucellosis with hepatomegaly and splenomegaly occurring in about 20 to $30 \%$ of the cases ${ }^{1,3}$. There is frequent involvement of bones and joints resulting in focal complications such as sacroiliitis, spondylitis, peripheral arthritis and osteomyelitis ${ }^{1}$. The most serious complication is infectious endocarditis that occurs in $1 \%$ of the cases and is responsible for most of the $5 \%$ mortality rate of human brucellosis $^{1,3}$. Blood culture is the gold standard for diagnosing brucellosis, but serological tests are also very useful ${ }^{1}$. Rose Bengal test (a rapid slidetype agglutination assay) is commonly used as a

Doctor, Hospital Eduardo de Menezes. Department of Infectious Diseases, Belo Horizonte (MG), Brasil.

Medical resident, Hospital Eduardo de Menezes. Department of Infectious Diseases, Belo Horizonte (MG), Brasil.

Graduate student, Universidade José do Rosário Vellano, Belo Horizonte (MG), Brasil. 
screening test and positive results are confirmed by the serum agglutination test ${ }^{4}$.

Enzyme-Linked Immunosorbent Assay (ELISA) has become more commonly used and it seems to have good sensitivity but lower specificity compared to agglutination tests ${ }^{1}$. Polymerase chain reaction (PCR) tests also have high sensitivity, but their higher costs limit their use in clinical practice ${ }^{5}$.

Treatment of brucellosis requires the use of at least two drugs and the most effective dual combination seems to be a tetracycline (doxycycline or tetracycline) with an aminoglycoside (gentamycin or streptomycin) ${ }^{6}$. Rifampicin may be used in combination with doxycycline as an alternative treatment ${ }^{6,7}$. Regarding prevention, effective vaccines are only available for cattle and goats. In Brazil, the National Program for Control and Eradication of Brucellosis / Animal Tuberculosis (PNCEBT) was established in 2001 and recommended vaccination of female bovine animals with B19 vaccine ${ }^{8}$. This vaccine contains live-attenuated strains of Brucella abortus. Therefore, accidental exposure poses a potential risk for human infection ${ }^{8-10}$. This risk of infection seems to be low but appropriate post-exposure prophylaxis is recommended ${ }^{11}$. Here, we report on a case of accidental exposure to brucellosis vaccine with seroconversion despite prophylaxis.

\section{CASE REPORT}

A 28-year-old male, veterinarian, presented to an infectious disease clinic with a history of perforation of the left hand while vaccinating cattle 12 hours earlier. The vaccine involved in the exposure was BRUCEL-VET, a lyophilized suspension of live germs of Brucella abortus (sample B19). The patient was asymptomatic. Previous medical history included the use of pantoprazole $(40 \mathrm{mg} / \mathrm{d})$ for treatment of epigastric pain two months before. The vaccination schedule was complete. A regimen of doxycycline (100 $\mathrm{mg}$ twice a day) and rifampin (600 mg once a day) for 42 days was prescribed for post-exposure prophylaxis (PEP). Baseline ELISA immunoglobulin (Ig) serology for Brucella was non-reactive $(5 \mathrm{U} / \mathrm{ml}$; cut-off value: $30 \mathrm{U} / \mathrm{ml}$ ) and liver and renal profile were within normal range.
Five days after beginning PEP, the patient sought medical attention complaining of nausea, epigastralgia, myalgia and headache, which he attributed to the medications. The patient was advised to take the medications with food to avoid gastrointestinal distress and suspend rifampin if there was no improvement. After 7 days of use, the patient discontinued rifampin with complete resolution of gastrointestinal symptoms and maintained doxycycline as prescribed for 42 days. The patient was asymptomatic at the end of the prophylaxis but showed seroconversion (IgM $43 \mathrm{U} / \mathrm{ml}$ - cut-off value: $20 \mathrm{U} / \mathrm{ml}$; IgG $47 \mathrm{U} / \mathrm{ml}$ - cut-off value $30 \mathrm{U} / \mathrm{ml}$ ). Conventional blood culture with prolonged incubation time (30 days) was performed (three samples), which showed no bacterial growth. Polymerase chain reaction for Brucella was not available. During the 6-month follow-up period the patient remained asymptomatic. This study was approved by the Hospital Eduardo de Menezes Institutional Review Board (protocol number 3.847.964). The requirement for the investigator to obtain a signed consent form was waived by the IRB.

\section{DISCUSSION}

Brucella abortus (strain B19) vaccine is part of the mandatory sanitary measures recommended by the National Program for Control and Eradication of Brucellosis and Animal Tuberculosis in Brazil, and the reported patient was exposed while routinely vaccinating cattle. Accidents during the administration of live attenuated brucellosis vaccines with dermal inoculation are of high risk for human infection and post-exposure prophylaxis is indicated $^{9-11}$. In the medical literature there are few studies describing the outcome of accidental exposure to brucellosis vaccine. In a series of 26 cases exposed to Brucella abortus (strain RB51) vaccine, $81 \%$ were associated with needlestick injury, $15 \%$ with conjunctival spray exposure and $4 \%$ reported direct contact with an open wound, and at least one systemic symptom was reported by $73 \%$ of the exposed workers ${ }^{12}$.

The need for post-exposure prophylaxis is called into question by studies that show a low rate of active brucellosis ( 0 to $2 \%$ ) in laboratory employees exposed to $B$. melitensis even among 
those not receiving PEP2. Since PEP may be associated with side effects, more research is needed to assess the potential effectiveness of PEP after brucellosis exposure.

In Brazil, there are two different recommendations for PEP after accidental exposure to Brucellosis. The Santa Catarina State Protocol for Surveillance and Clinical Management of Human Brucellosis ${ }^{11}$ proposes a more conservative approach and does not recommend antimicrobial prophylaxis after percutaneous exposure to the vaccine. It recommends following up with the exposed patient for 2 years in a reference medical center where non-specific laboratory tests should be performed (aminotransferases and inflammation blood tests). Treatment is recommended for patients presenting brucellosis-related symptoms or with altered blood tests. On the other hand, the Paraná State Protocol ${ }^{9}$ recommends immediate PEP for occupational exposures to Brucella vaccine, regardless of the strain. For needlestick injuries, the protocol recommends the use of doxycycline $100 \mathrm{mg}$ twice a day for 42 days. In the United States(US), the Centers for Disease Control and Prevention (CDC) recommends the use of rifampin $600 \mathrm{mg} / \mathrm{d}$ combined with doxycycline for high-risk post-exposure prophylaxis, such as after percutaneous exposure, but indicates a shorter period of three weeks. In addition to prophylaxis, it is always important to recommend wound care and check the status of tetanus vaccination after a percutaneous exposure ${ }^{8}$.

In the current reported case, we chose to follow the drug association proposed by the CDC but for the duration of time recommended by the Paraná State Protocol. However, because of significant gastrointestinal intolerance to rifampin, the patient completed PEP only with doxycycline as proposed by the Paraná protocol. After six months of follow-up, the patient had no signs or symptoms of brucellosis infection, but the seroconversion suggests that the patient was indeed infected. As the patient completed 42 days of doxycycline and remained asymptomatic at the end of PEP, no additional treatment was indicated but he was followed-up for 6 months.

As exposure to brucella vaccine is an unusual situation, it is comprehensible that there are few recommendations based on good quality evidence on how to proceed. The different recommendations for the management of brucella exposure reinforce the need for more studies. In our experience, we have observed that PEP is not free from side effects, and a risk-benefit analysis should be considered. In our reported case, early use of antibiotics may have been beneficial as seroconversion suggests that the patient was indeed infected, and we expect that the combination of doxycycline and rifampin may prevent future complications. Our study is relevant to public health in the interface between human and animal health. The vaccination is an important preventive measure against bovine brucellosis, but accidental human exposure to the vaccine strain can bring serious health problems. The reported case contributes to a better understanding of the subject by showing that prophylaxis can prevent the disease, but does not prevent infection from occurring. The risk of future reactivation of the microorganism in those exposed to the vaccine strain should be assessed with long-term follow-up studies.

\section{REFERENCES}

1. Franco MP, Mulder M, Gilman RH, Smits HL. Human brucellosis. Lancet Infect Dis. 2007;7(12):775-86.

2. Traxler RM, Guerra MA, Morrow MG, Haupt T, Morrison J, Saah JR, et al. Review of Brucellosis Cases from Laboratory Exposures in the United States in 2008 to 2011 and Improved Strategies for Disease Prevention. J ClinMicrobiol. 2013;51(9):3132-36.

3. Dean AS, Crump L, Greter H, Hattendorf J, Schelling E, Zinsstag J. Clinical Manifestations of Human Brucellosis: A Systematic Review and Meta-Analysis. PLoSNegl Trop Dis. 2012;6:1-9.

4. Al Dahouk S, Tomaso $H$, Nockler $K$, Neubauer $H$, Frangoulidis D. Laboratory-based diagnosis of brucellosis - a review of the literature. Part II: serological tests for brucellosis. Clin Lab. 2003;49:577-89.

5. Probert WS, Schrader KN, Khuong NY, Bystrom SL, Graves MH. Real-time multiplex PCR assay for detection of Brucella spp,Babortus, and B melitensis. J ClinMicrobiol. 2004;42:1290-93.

6. Skalsky K1, Yahav D, Bishara J, Pitlik S, Leibovici L, Paul M.Treatment of human brucellosis: systematic review and meta-analysis of randomised controlled trials. BMJ. 2008;336(7646):701-4.

7. Solera J. Update on brucellosis: therapeutic challenges. Int J Antimicrob Agents. 2010;36(1):18-20. 
8. Hyeda $A$, Sbardellotto $F$. Exposição acidental à vacina da brucelose. Rev Bras Med Trab. 2011;9(2):62-8.

9. Santa Catarina. Diretoria de vigilância Epidemiológica. Protocolo estadual de vigilância e manejo clínico de brucelose humana. Santa Catarina (DVE); 2012.11-13 p.

10. Centers for Disease Control and Prevention (CDC). Brucellosis reference guide: exposures, testing, and prevention, Atlanta: CDC; 2017. 40 p.
11. Tuon FF, Cerchiari N, Cequinel JC, Droppa EEH, Moreira SDR, Costa TP, et al. Guidelines for the management of human brucellosis in the State of Paraná, Brazil. Rev Soc Bras Med Trop. 2017;50(4):458-64.

12. Seyman D, Asik Z, Sepin-Ozen N, Berk H. Acute Brucellosis Following Accidental Exposure to Brucella melitensis Rev 1 Vaccine.West Indian Med J. 2015;65(1):216-18.

\section{Funding}

Own financing.

Corresponding author:

Dr. Alexandre Sampaio Moura

alexandresmoura@gmail.com

Editor:

Prof. Dr Felipe Villela Gomes

Received in: Mar 22, 2020

Approved in: Oct 07, 2020

(c) (i) Este é um artigo publicado em acesso aberto (Open Access) sob a licença Creative 